\title{
Difficulties in Emotion Regulation and Mindfulness in Psychological and Somatic Symptoms of Functional Gastrointestinal Disorders
}

\author{
Mina Mazaheri ${ }^{1, *}$ \\ ${ }^{1}$ Psychosomatic Research Center, Isfahan University of Medical Sciences, Isfahan, IR Iran \\ ${ }^{*}$ Corresponding author: Mina Mazaheri, Psychosomatic Research Center, Isfahan University of Medical Sciences, Isfahan, IR Iran. Tel: +98-9133254633, Fax: +98-3136289966, \\ E-mail: mina.mazaheri@gmail.com
}

Received 2014 November 10; Revised 2015 February 28; Accepted 2015 September 16.

\begin{abstract}
Background: Negative emotions are the best predictors for psychological and physical health.

Objectives: We aimed to investigate the role of difficulties in emotion regulation and mindfulness on psychological and somatic symptoms of patients with functional gastrointestinal disorders (FGID).

Patients and Methods: In this cross-sectional study, the studied sample was selected using census method. A total of 167 patients with FGID completed a demographic questionnaire, difficulties in emotion regulation scale (DERS), mindful attention awareness scale (MAAS), depression, anxiety and stress scale (DASS), and gastrointestinal symptom rating scale (GSRS). To examine the relationship between studied variables, Pearson correlation coefficients and multiple regression analyses were used.

Results: The findings of the study indicate that difficulties in emotion regulation and mindfulness are significantly correlated to both increased psychological and somatic symptoms. Some factors of difficulties in emotion regulation positively predicted those symptoms. Among these factors, only lack of awareness was not significantly correlated with both symptoms as well as decreased mindfulness. Conclusions: The findings suggest some potential targets to reduce symptoms. Patients with FGID may benefit from treatments that facilitate emotional experience, functional status, and ability to control impulsive behaviors and behave according to the goals when experiencing negative emotions.

Keywords: Emotional Disturbances, Functional Gastrointestinal Disorders, Mindfulness, Psychological Aspects, Somatic Symptoms
\end{abstract}

\section{Background}

In recent years, there is an increasing attention to the issue of emotion regulation as psychopathology mechanism of various psychological problems, and also as the main target of treatment. Despite the interest, there is not agreement on the definition of emotion regulation, which has been inconsistently defined in the different studies. Emotion regulation has rooted in analytical psychology, stress and coping strategies (1). Some concepts of emotion regulation emphasize the ability to control emotional experience and expression of negative emotions $(2,3)$. Unlike other concepts, stress on the functional nature of emotions has suggested that adaptive emotion regulation involves the ability to control behaviors (e.g. by engaging in goal-directed behaviors and or inhibiting impulsive behaviors) rather than just controlling emotions in the face of negative emotions $(4,5)$. In fact, lack of the ability to experience and differentiate emotions and also spontaneous responses may be maladaptive similar to disability in reducing and regulating intense negative emotions $(6,7)$. Previous research shows that difficulties in emotion regulation (emotional dysregulations) are key factors in developing many clinical behaviors and psychological problems (8). Furthermore, emotional dysregulation have been iden- tified in numerous forms of psychopathology, ranging from affective disorders to personality disorders (6) such as generalized anxiety disorder (GAD) (9), depression (10), anxiety (11), borderline personality disorder (12), social anxiety (13), substance use (14), and psychosomatic disorders (e.g. functional gastrointestinal disorders)(15). Moreover, it appears that emotion regulation is related to somatic distresses. Study upon patients with functional gastrointestinal disorders (FGID) indicated that some factors involved in emotional dysregulation (difficulties engaging in goaldirected behavior and lack of emotional awareness) are predictors of decreased acceptance of pain (15). Experimental research has also shown that affect-based treatments and or interventions based on emotion regulation are effective in reduction severity of somatic symptoms besides emotions (e.g. anxiety and depression) (16-18).

Furthermore, in the domains of emotion research and in the context of interventions for clinical problems, further attention has been paid to the concept of mindfulness and its practices. It is believed that the main cause of human distress is judging events as "good versus bad" (19). Also, it is assumed that mindfulness has a major impact on the release of individuals from their thoughts,

Copyright (C) 2015, Mazandaran University of Medical Sciences. This is an open-access article distributed under the terms of the Creative Commons Attribution-NonCommercial 4.0 International License (http://creativecommons.org/licenses/by-nc/4.0/) which permits copy and redistribute the material just in noncommercial usages, provided the original work is properly cited. 
habits and unhealthy behaviors (20) because it implies non-judgmental and nonreactive acceptance of emotional states (21). Hence, mindfulness increases self-regulated behavior related to improvement of well-being (20). Studies have shown that mindfulness negatively correlates with psychological symptoms of distress such as anxiety and depression, and positively with various forms of psychological well-being $(22,23)$.

The useful effects of mindfulness-based interventions, such as mindfulness-based cognitive therapy (MBCT), especially mindfulness-based stress reduction (MBSR), on human well-being have been confirmed in several studies (2426). Mindfulness practices can enhance functional status, well-being, and reduce physical or psychological distresses (25). Speca et al. (26) reported fewer symptoms of stress; fewer somatic symptoms (cardiopulmonary and gastrointestinal); less emotional irritability, depression, and cognitive disturbance; and fewer habitual patterns of stress, after mindfulness-based intervention in cancer outpatients.

Since both mindfulness and emotion regulation influence different aspects of well-being, these two constructs might be related to each other and some aspects of this relationship were demonstrated during some studies (19, 21). Emotion regulation overlaps with mindfulness, in its emphasis on observing and describing emotions (without necessarily acting on those emotions), and also participating in present moment activities (i.e. engaging in goal-directed behavior when distressed) (8). The findings of the previous studies suggest that mindfulness can conduce to better emotional condition by reducing negative affectivity and various difficulties related to emotion (21). It induces self-regulatory behaviors and increases experiences of positive emotional states (27).

Because emotional disturbances are present in many patients with FGID (as psychosomatic disorders), particularly in referral population, this study aimed to evaluate relationships of emotion regulation difficulties and mindfulness with psychological and digestive symptoms in those patients. Although some aspects of the relationship between mindfulness and emotion regulation have already been investigated, some other aspects still need to be studied. For instance, the association between the factors involved in emotion regulation and mindfulness has not been investigated yet.

\section{Objectives}

Hence, the main goal of the study was to examine the role of difficulties in emotion regulation and mindfulness in psychological and somatic symptoms of patients with FGID.

\section{Patients and Methods}

\subsection{Participants}

In this cross-sectional study, 167 patients with FGID referred to the psychosomatic disorders clinic of Isfahan were selected by census method, according to criteria of research. Study criteria included willingness to participate in the study, age range of 18 - 70 years, lack of acute psychiatric disorders, and the diagnosis of FGID on the basis of ROME III criteria by gastroenterologists. To observe ethical considerations, the researcher assured to patients of the confidentiality of their information.

\subsection{Measures}

\subsubsection{Demographic Information}

In current study, demographic information included age, sex, marital status, and educational level.

\subsubsection{Difficulties in Emotion Regulation Scale}

The difficulties in emotion regulation scale (DERS) assesses difficulties in emotion regulation and can distinguish adaptive emotion regulation from emotional avoidance and expressive control. The scale is composed of 6 factors, including, non-acceptance of emotional responses (non-acceptance), difficulties engaging in goal-directed behavior (goal), impulse control difficulties (impulse), lack of emotional awareness (awareness), limited access to emotion regulation strategies (strategy), and lack of emotional clarity (clarity). DERS has 36 items that are rated on a 5-point Likert-type scale, ranging from 1 (almost never) to 5 (almost always), and are recoded so that higher scores in every case indicate greater difficulties in emotion regulation. The scale has high internal consistency; Cronbach $\alpha=$ 0.93 for total DERS and Cronbach $\alpha>0.80$ for each factors; also its test-retest equals 0.87 for total DERS and ranges from 0.69 to 0.89 for all factors (28). In an Iranian healthy sample, internal consistency of the scale using Cronbach $\alpha$ ranged from 0.66 to 0.88 for all factors (29). With regard to validity, studies have suggested sufficient construct and predictive validity to the scale (28).

\subsubsection{Mindful Attention Awareness Scale}

Mindful attention awareness scale (MAAS) is a 15 -item self-report measure of the present moment attention and awareness. Items reflect in attention across several domains (e.g. cognitive, emotional, physical, and general). Each item rates over a 6-point Likert-type scale, with 6 indicating "almost never" and 1 indicating "almost always." So, high scores reflect higher levels of present moment attention. It has been revealed a single-factor model for the scale, along with good internal consistency $(\alpha=0.82)$ and temporal stability (27). In this sample, Cronbach $\alpha$ coefficient was equivalent to 0.84 .

\subsubsection{Short Form of Depression, Anxiety, and Stress Scale}

The initial version of the depression, anxiety, and stress scale (DASS) contained 42 phrases about negative emotional states. The scale measures the intensity of depression, anxiety, stress symptoms and can be used to assess 
treatment progression. Subject rates intensity (frequency) of symptom presented in each phrase which he or she has experienced over the past week over a 4-point Likert scale, ranging from 0 (did not apply to me at all) to 3 (applied to me very much). Cronbach $\alpha$ values have been reported for depression, anxiety, and stress as 0.91 , $0.81,0.89$, respectively (30). The internal consistency reliability of short form of the 21-DASS (each of its subscales comprises 7 items) was computed in an Iranian sample and Cronbach $\alpha$ values for depression, anxiety, and stress were $0.81,0.74,0.78$, respectively (31).

\subsubsection{Gastrointestinal Symptom Rating Scale}

The gastrointestinal symptom rating scale (GSRS) is a disease-specific instrument of 15 items, with 5 subscales (symptom clusters), including abdominal pain, reflux, diarrhea, constipation, and indigestion. The GSRS is rated on a 7-point Likert-type scale, ranging from 1 (no discomfort at all) to 7 (very severe discomfort). Based on Cronbach $\alpha$, the internal consistency validities of total GSRS and its subscales have been reported as $0.62,0.61,0.83$, 0.80 , and 0.70 , respectively (32). Furthermore, in an Iranian sample of patients with FGID, Cronbach $\alpha$ values of the GSRS and the subscales of diarrhea, abdominal pain, constipation, indigestion were equivalent to $0.81,0.70$, $0.70,0.63,0.76$, respectively (33).

\subsection{Statistical Analyses}

Descriptive analyses were presented as mean and standard deviation. Pearson correlation coefficient was used to test the relation between emotional dysregulation (difficulties in emotion regulation), mindfulness and symptoms. Multiple regression analyses were performed to determine the predictive ability of studied variables. The dependent variables were psychological and somatic symptoms and mindfulness; the independent variables were emotional dysregulation and its factors and mind- fulness. The SPSS version 15.0 (SPSS Inc., Chicago, IL, USA) was used for statistical analyses.

\section{Results}

In the study, 167 patients with FGID participated with the following characteristics: mean (SD) age of 33.81(10.56) years; 135 (80.8\%) female; 69 (41.6\%) graduated; and 14 (74.3\%) married. The demographic information are presented in Table 1.

Descriptive statistics (mean \pm SD) and correlation coefficients between variables are presented in Table 2. Difficulties in emotion regulation, on the whole and in parts, except "awareness" factor were significantly and positively correlated with severity of psychological symptoms. They also (except awareness and clarity factors) were significantly and positively correlated with severity of digestive symptoms. Additionally, mindfulness was significantly and inversely correlated with both aspects of psychological and somatic symptoms. So, mindfulness was associated with less psychological and digestive symptoms severity. In addition, mindfulness was negatively correlated with difficulties in emotion regulation and its factors (except awareness).

\begin{tabular}{|c|c|}
\hline Demographic Characteristics & Values \\
\hline $\operatorname{Age}^{\mathrm{a}}$ & $33.81 \pm 10.56$ \\
\hline \multicolumn{2}{|l|}{ Gender ${ }^{b}$} \\
\hline Male & $32(19.2)$ \\
\hline Female & $135(80.8)$ \\
\hline \multicolumn{2}{|l|}{ Educational level ${ }^{b}$} \\
\hline Undergraduate & $97(58.4)$ \\
\hline Graduate & $69(41.6)$ \\
\hline \multicolumn{2}{|l|}{ Marital status $\mathbf{b}$} \\
\hline Married & $124(74.3)$ \\
\hline Unmarried & $43(25.7)$ \\
\hline
\end{tabular}

Table 2. Descriptive Statistics and Correlations Among Study Variables ${ }^{\mathrm{a}}$

\begin{tabular}{|c|c|c|c|c|c|c|c|c|c|c|c|c|c|}
\hline Variables & Mean (SD) & $\mathbf{1}$ & 2 & 3 & 4 & 5 & 6 & 7 & 8 & 9 & 10 & 11 & 12 \\
\hline MAAM & $3.7(0.87)$ & & $-0.58^{\mathrm{b}}$ & $-0.47^{b}$ & $-0.47^{b}$ & $-0.57^{b}$ & -0.008 & $-0.44^{b}$ & $-0.49^{b}$ & $-0.45^{\mathrm{b}}$ & $-0.50^{b}$ & $-0.50^{b}$ & $-0.28^{\mathrm{b}}$ \\
\hline Total DERS & $1.04 \mathrm{E} 2(22.9)$ & & & $0.66^{\mathrm{b}}$ & $0.70^{\mathrm{b}}$ & $0.66^{\mathrm{b}}$ & $0.25^{\mathrm{b}}$ & $0.62^{\mathrm{b}}$ & $0.58^{\mathrm{b}}$ & $0.51^{\mathrm{b}}$ & $0.54^{\mathrm{b}}$ & $0.58^{\mathrm{b}}$ & $0.35^{b}$ \\
\hline DERS non-accept & $19(6.2)$ & & & & $0.55^{b}$ & $0.40^{\mathrm{b}}$ & -0.14 & $0.49^{\mathrm{b}}$ & $0.24^{\mathrm{b}}$ & $0.42^{\mathrm{b}}$ & $0.50^{\mathrm{b}}$ & $0.46^{\mathrm{b}}$ & $0.30^{\mathrm{b}}$ \\
\hline DERS goal & $17.38(4.5)$ & & & & & $0.55^{\mathrm{b}}$ & -0.03 & $0.55^{\mathrm{b}}$ & $0.26^{\mathrm{b}}$ & $0.42^{\mathrm{b}}$ & $0.47^{\mathrm{b}}$ & $0.52^{\mathrm{b}}$ & $0.38^{\mathrm{b}}$ \\
\hline DERS impulse & $16.2(5.89)$ & & & & & & 0.12 & $0.49^{\mathrm{b}}$ & $0.40^{\mathrm{b}}$ & $0.39^{\mathrm{b}}$ & $0.51^{\mathrm{b}}$ & $0.53^{b}$ & $0.36^{\mathrm{b}}$ \\
\hline DERS awareness & $15.3(4.6)$ & & & & & & & -0.11 & $0.33^{\mathrm{b}}$ & 0.12 & -0.07 & -0.01 & -0.03 \\
\hline DERS strategy & $24.4(5.99)$ & & & & & & & & $0.28^{\mathrm{b}}$ & $0.40^{\mathrm{b}}$ & $0.52^{\mathrm{b}}$ & $0.52^{\mathrm{b}}$ & $0.29^{\mathrm{b}}$ \\
\hline DERS clarity & $13.2(4.06)$ & & & & & & & & & $0.37^{b}$ & $0.31^{b}$ & $0.42^{\mathrm{b}}$ & 0.10 \\
\hline D & $14.8(9.13)$ & & & & & & & & & & $0.64^{\mathrm{b}}$ & $0.70^{\mathrm{b}}$ & $0.26^{\mathrm{b}}$ \\
\hline A & $14.8(10.21)$ & & & & & & & & & & & $0.70^{\mathrm{b}}$ & $0.42^{\mathrm{b}}$ \\
\hline $\mathbf{S}$ & $20.2(10.22)$ & & & & & & & & & & & & $0.37^{\mathrm{b}}$ \\
\hline GSRS & $13.22(4.29)$ & & & & & & & & & & & & \\
\hline
\end{tabular}

Abbreviations: A, anxiety; D, depression; DERS, the difficulties in emotion regulation scale; S, stress; GSRS, gastrointestinal symptom rating scale; MAAM, mindful attention awareness scale.

a 1, MAAM; 2, total DERS; 3, DERS-non-accept; 4, DERS-goal; 5, DERS-impulse; 6, DERS-awareness; 7, DERS-strategy; 8, DERS-clarity; 9, D; 10, A; 11, S; 12, GSRS. $\mathrm{b}_{\mathrm{P}<0.01 .}$ 
Afterwards, to examine whether the factors of difficulties in emotion regulation (DERS) and mindfulness (MAAS) predict independent variances in the severity of both aspects of symptoms, we performed stepwise multiple regression analyses. In the first step of regression, DERS (total and its factors) were entered as the sole predictors of symptoms, and in the next step, mindfulness was entered. The final steps of regression analyses are presented in the Tables 3 and 4.

As it can be seen in Table 3, the results showed that only variables of goal and impulse remained as significantly independent predictors for somatic symptoms. The model accounted for $17.7 \%$ of the variance. Mindfulness was not a significant predictor of symptoms with levels of DERS controlled and did not significantly improve the model.

Table 3. The Final Step of Regression Analysis of DERS, MAAS, and GSRS $^{\mathrm{a}}$

\begin{tabular}{lcccc}
\hline Variables & Beta & $\mathbf{t}$ & PValue & $\mathbf{R}^{\mathbf{2}}$ \\
\hline DERS goal & 0.236 & 2.657 & .009 & .174 \\
DERS impulse & 0.196 & 2.055 & .012 & .174 \\
MAAS & -0.058 & -0.640 & .523 & .002 \\
\hline
\end{tabular}

Abbreviations: DERS, The difficulties in emotion regulation scale; MAAM, mindful attention awareness scale; GSRS, gastrointestinal symptom rating scale.

a Predictors: DERS-goal, DERS-impulse, MAAS; Dependent variable: GSRS.

Table 4. The Final Step of Regression Analysis of DERS, MAAS, and DASS $^{\mathrm{a}}$

\begin{tabular}{lcccc}
\hline Variables & Beta & $\mathbf{t}$ & PValue & $\mathbf{R}^{\mathbf{2}}$ \\
\hline $\mathbf{D}^{\mathbf{a}}$ & & & & \\
\multicolumn{1}{c}{ DERS } & 0.357 & 4.309 & .0001 & .264 \\
\hline MAAS & -0.246 & -2.989 & .003 & .033 \\
\hline Age & -0.094 & -1.398 & .164 & .009 \\
\hline $\mathbf{b}$ & & & & \\
\hline DERS strategy & 0.241 & 3.183 & .002 & .415 \\
\hline DERS impulse & 0.193 & 2.456 & .015 & .415 \\
\hline DERS non-accept & 0.191 & 2.600 & .010 & .415 \\
\hline MAAS & -0.199 & -2.572 & .011 & .018 \\
\hline Age & -0.138 & -2.239 & .027 & .018 \\
\hline $\mathbf{C}$ & & & & \\
\hline DERS & & & .004 & .371 \\
\hline DERS strategy & 0.258 & 3.272 & .001 & .371 \\
\hline MAAS & -0.225 & -2.963 & .003 & .028 \\
\hline Age & -0.165 & -2.672 & .008 & .026 \\
\hline
\end{tabular}

Abbreviations: D, depression; A, anxiety; S, stress; DERS, the difficulties in emotion regulation scale; MAAM, mindful attention awareness scale.

a Dependent variable: D; Predictors: DERS, MAAS and age.

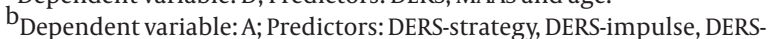

non-accept, MAAS and age.

${ }^{\mathrm{C}}$ Dependent variable: S; Predictors: DERS, D5, MAAS and age.
Table 5. The Final Step of Regression Analysis Between Difficulties in Emotion Regulation and Mindfulness ${ }^{\mathrm{a}}$

\begin{tabular}{lcccc}
\hline Variables & Beta & $\mathbf{t}$ & P Value & $\mathbf{R}^{2}$ \\
\hline DERS impulse & -0.346 & -5.167 & .0001 & .460 \\
DERS clarity & -0.280 & -4.412 & .0001 & .460 \\
DERS non-accept & -0.269 & -4.262 & .0001 & .460 \\
\hline
\end{tabular}

Abbreviation: MAAM: mindful attention awareness scale.

a Dependent variable: MAAS; Predictors: DERS-impulse, DERS-clarity, DERS-non-accept.

Whereas age was correlated with psychological symptoms (especially anxiety and stress) for controlling, it was entered in regression equations. The findings showed that in addition to total DERS and some of its factors, mindfulness was also a predictor for depression, anxiety, and stress. It significantly improved the models, contributing an additional 3.3\%, 1.8\%, $2.8 \%$ of the variance for $\mathrm{D}, \mathrm{A}$, and $S$, consecutively (Table 4 ). In general, results showed that difficulties in emotion regulation played the main role in prediction of the severity of psychological and somatic (digestive) symptoms and some factors acted as independent predictors (e.g. impulse, strategy).

We performed other stepwise multiple regression analyses to examine whether the factors of difficulties in emotion regulation predict independent variances for mindfulness. As it can be seen in Table 5, three factors of impulse, clarity, and non-accept acted as negatively significant predictors of mindfulness.

\section{Discussion}

Determination of the role of difficulties in emotion regulation and mindfulness in psychological and somatic symptoms are important. According to Gratz and Tull (8), the difficulties in clinical disorders and maladaptive behaviors would have important implications for the development of more targeted interventions. Although the issue of difficulties in emotion regulation and mindfulness has been assessed in some psychiatric and medical disorders, this study was the first to examine the relationship between mindfulness and especially difficulties in emotion regulation with psychological and somatic (digestive) symptoms in FGID.

As predicted, the findings of the study revealed positive significant associations between emotional dysregulation and most of its factors with psychological and somatic symptoms. Regression analyses showed that some viewed variables can predict these symptoms (i.e. the relationships remained when shared variance associated with other variables and also age was accounted). In other words, difficulties engaging in goal-directed behavior, difficulties in impulsive behaviors control, limited access to emotion regulation strategies, and non-acceptance of emotional responses were the most powerful factors in relation to symptoms. Studies have shown that emotion regulation skills (e.g. emotional acceptance, ability to en- 
gage in goal-directed behavior, adaptive strategies) are associated with lower emotional problems $(34,35)$.

As a note, in this study psychological and somatic symptoms were not correlated with the lack of awareness factor. It is contrary to some previous research that has been revealed awareness an important factor, which has positive or negative effect on emotion regulation process and some somatic symptoms $(15,36,37)$. However, our finding is consistent with Salters-Pedneault et al. (9) study that found all dimensions of emotion regulation difficulties (with the exception of lack of emotional awareness) were significantly elevated among individuals with GAD. According to Bardeen et al. (38), DERS awareness may sufficiently measure emotional awareness, but lack of emotional awareness is not necessarily associated with distress or attention to emotional states does not necessarily represent a healthy response or regulation of such states.

Also, our findings indicated that mindfulness were negatively correlated to both symptoms, however it was stronger for psychological symptoms. Such results highlight the obvious benefits of mindfulness among patients and confirm the results of previous studies $(20,22,23)$. Mindfulness interventions can alleviate the symptoms of physical and psychiatric disorders $(26,39)$. Investigations have shown improvements in mental health measures, including psychological dimensions of quality of life, depression, anxiety, coping style and other affective dimensions of disability, and in some health parameters of physical well-being such as medical symptoms, sensory pain, and physical impairment $(40,41)$.

In evaluating the relationship between difficulties in emotion regulation and mindfulness, the findings showed that DESR total score and most of its factors were negatively correlated with mindfulness and this relationship remained for factors of non-accept, impulse, and clarity when controlling for variance shared with the others. Erisman et al. (42) showed that mindfulness had significant relationships with emotion regulation on the whole and also with impulse control and goal attainment difficulties when distressed. When people experience negative emotions, they encounter problems in goal-oriented behavior (such as loss of concentration or effective problem solving) (43). Coffey et al. (44) identified clarity of internal experiences as a partial mediator of the relationship between mindfulness and negative affect regulation.

However in their conceptual definitions, both mindfulness and emotion regulation difficulties included awareness and acceptance of emotional responses, but the findings showed that mindfulness was not significantly correlated with DERS awareness. Awareness of or attention to emotions as assessed in emotion regulation scales may not correspond to reduced clinical problems or increased well-being $(45,46)$. So, should this concept be valid, self-reported lack of awareness in DERS alone may not be related to awareness of the present moment in mindfulness, because mindfulness includes awareness of emotional experiences with an attitude of acceptance and nonjudging (21). Thus, in processing the relationship between mindfulness and emotional dysregulation, that ingredient of acceptance of emotional responses may be more influential.

The main limitations of this study were non-random sampling (because of limited statistical population) and reliance on self-report data which may be recall bias regarding the occurrence of symptoms. Also, other social factors that may affect the relationship between variables have been overlooked. So, we should be cautious in generalizing the findings.

Overall, the findings of the study indicate that the constructs of emotion regulation difficulties (emotional dysregulation) and mindfulness are related to both psychological and somatic symptoms in FGID, but some factors of dysregulation have more influential role in relation to increased symptoms as well as decreased mindfulness. The findings suggest potential targets for treatment. Patients with FGID may benefit from treatments that facilitate emotional experience, functional status, and ability to control impulsive behaviors. They can behave according to the goals when experiencing negative emotions (i.e. emotion regulation skills). To reduce symptoms, treatments might further towards emotion regulation, and mindfulness practices can be utilized as one of the strategies or skills of emotion regulation.

Although more research is needed to uphold conclusions, the study can be a thoroughfare for future research in more examination of influential factors in poor emotion regulatory ability and their roles in developing psychological and somatic symptoms in physical disorders.

\section{Authors' Contributions}

Mina Mazaheri conceived and designed the study, collected and interpreted the data and performed the statistical analysis, drafted, and revised the manuscript and approved the final version of the manuscript.

\section{Declaration of Interest}

None declared.

\section{References}

1. Dubey A, Pandey R, Mishra K. Role of Emotion R Emotion R Emotion Regulation Difficulties and P iculties and P iculties and Positive/Negative Affectivity in Explaining Alexithymia-Health Relationship: An overview. J Soc Sci Res. 2010;7(1):20-31.

2. Kopp CB. Regulation of distress and negative emotions: A developmental view. Developmental psychology. 1989;25(3):343. doi: 10.1037/0012-1649.25.3.343

3. Zeman J, Garber J. Display rules for anger, sadness, and pain: it depends on who is watching. Child Dev. 1996;67(3):957-73. [PubMed: 8706538]

4. Linehan M. Cognitive-behavioral treatment of borderline personality disorder. New York: Guilford Press; 1993.

5. Melnick SM, Hinshaw SP. Emotion regulation and parenting in $\mathrm{AD} / \mathrm{HD}$ and comparison boys: linkages with social behaviors 
and peer preference. J Abnorm Child Psychol. 2000;28(1):73-86. [PubMed: 10772351]

6. Gross JJ, Muñoz RF. Emotion Regulation and Mental Health. Clin Psychol: Sci Pr. 1995;2(2):151-64. doi: 10.1111/j.1468-2850.1995. tbo0036.x.

7. Cole PM, Michel MK, Teti LO. The development of emotion regulation and dysregulation: a clinical perspective. Monogr Soc Res Child Dev. 1994;59(2-3):73-100. [PubMed: 7984169]

8. Gratz KL, Tull MT. Emotion regulation as a mechanism of change in acceptance-and mindfulness-based treatments. In: Baer RA, editor. Assessing mindfulness and acceptance processes in clients: Illuminating the theory and practice of change. Oakland, CA: New Harbinger Publications; 2010. pp. 107-33.

9. Salters-Pedneault K, Roemer L, Tull MT, Rucker L, Mennin DS. Evidence of Broad Deficits in Emotion Regulation Associated with Chronic Worry and Generalized Anxiety Disorder. Cognit Ther and Res. 2006;30(4):469-80. doi:10.1007/s10608-006-9055-4.

10. Joormann J, Gotlib IH. Emotion regulation in depression: relation to cognitive inhibition. Cogn Emot. 2010;24(2):281-98. doi: 10.1080/02699930903407948. [PubMed: 20300538]

11. Vujanovic A, Zvolensky M, Bernstein A. The Interactive Effects of Anxiety Sensitivity and Emotion Dysregulation in Predicting Anxiety-related Cognitive and Affective Symptoms. Cognit Ther Res. 2008;32(6):803-17. doi:10.1007/s10608-007-9148-8.

12. Austin MA, Riniolo TC, Porges SW. Borderline personality disorder and emotion regulation: insights from the Polyvagal Theory. Brain Cogn. 2007;65(1):69-76. doi: 10.1016/j.bandc.2006.05.007. [PubMed: 17659821]

13. Goldin PR, Manber T, Hakimi S, Canli T, Gross JJ. Neural bases of social anxiety disorder: emotional reactivity and cognitive regulation during social and physical threat. Arch Gen Psychiatry. 2009;66(2):170-80. doi: 10.1001/archgenpsychiatry.2008.525. [PubMed: 19188539]

14. Fox HC, Hong KA, Sinha R. Difficulties in emotion regulation and impulse control in recently abstinent alcoholics compared with social drinkers. Addict Behav. 2008;33(2):388-94. doi: 10.1016/j.addbeh.2007.10.002. [PubMed: 18023295]

15. Mazaheri M, Mohammadi N, Daghaghzadeh H, Afshar H. The relationship of emotional dysregulation, personality traits (psychological hardiness, interpersonal forgiveness), and pain among patients with functional gastrointestinal disorders. Isfahan, Iran: Isfahan University of Medical Sciences; 2013.

16. Allen LB, Tsao JCI, Seidman LC, Ehrenreich-May J, Zeltzer LK. A Unified, Transdiagnostic Treatment for Adolescents With Chronic Pain and Comorbid Anxiety and Depression. Cognit Behav Pr. 2012;19(1):56-67. doi:10.1016/j.cbpra.2011.04.007.

17. Esmaeili L, Aghaei A, Abedi M, Esmaeili M. The effectiveness of emotion regulation training on Mental Health of girls with epilepsy. Thought Behav. 2011;5(20):42-31.

18. Bergdahl J, Armelius K, Armelius BA. Affect-based treatment and outcome for a group of psychosomatic patients. Sweden: Umea University, Department of Applied Psychology; 2000. Available from: http://media.ikp.armelius.com/2011/05/Affect-based-treatment-and-outcome.pdf.

19. Nyklicek I. Mindfulness, Emotion Regulation, and Well-Being. In: Nyklí ek I, Vingerhoets A, Zeelenberg M, editors. Emotion Regulation and Well-Being. New York: Springer ; 2011. pp. 101-18.

20. Ryan RM, Deci EL. On happiness and human potentials: a review of research on hedonic and eudaimonic well-being. Annu Rev Psychol. 2001;52:141-66. doi:10.1146/annurev.psych.52.1.141. [PubMed: 11148302]

21. Mandal SP, Arya YK, Pandey R. Mindfulness, emotion regulation and subjective wellbeing: An overview of pathways to positive mental health. Ind J Soc Sci Res. 2011;8(1-2):159-67.

22. Feldman G, Hayes A, Kumar S, Greeson J, Laurenceau JP. Mindfulness and Emotion Regulation: The Development and Initial Validation of the Cognitive and Affective Mindfulness Scale-Revised (CAMS-R). J Psychopathol Behav Assess. 2007;29(3):177-90. doi: 10.1007/s10862-006-9035-8.

23. Baer RA, Smith GT, Hopkins J, Krietemeyer J, Toney L. Using self-report assessment methods to explore facets of mindfulness. Assessment. 2006;13(1):27-45. doi: 10.1177/1073191105283504.
[PubMed: 16443717]

24. Mathew KL, Whitford HS, Kenny MA, Denson LA. The long-term effects of mindfulness-based cognitive therapy as a relapse prevention treatment for major depressive disorder. Behav Cogn Psychother. 2010;38(5):561-76. doi: 10.1017/S135246581000010X. [PubMed: 20374671]

25. Reibel DK, Greeson JM, Brainard GC, Rosenzweig S. Mindfulnessbased stress reduction and health-related quality of life in a heterogeneous patient population. Gen Hosp Psychiatry.23(4):183-92. doi:10.1016/S0163-8343(01)00149-9. [PubMed: 11543844]

26. Speca M, Carlson LE, Goodey E, Angen M. A randomized, wait-list controlled clinical trial: the effect of a mindfulness meditationbased stress reduction program on mood and symptoms of stress in cancer outpatients. Psychosom Med. 2000;62(5):613-22. [PubMed: 11020090]

27. Brown KW, Ryan RM. The benefits of being present: mindfulness and its role in psychological well-being.J Pers Soc Psychol. 2003;84(4):822-48. [PubMed: 12703651]

28. Gratz KL, Roemer L. Multidimensional Assessment of Emotion Regulation and Dysregulation: Development, Factor Structure, and Initial Validation of the Difficulties in Emotion Regulation Scale.J Psychopathol Behav Assess. 2004;26(1):41-54. doi:10.1023/B: JOBA.0000007455.08539.94.

29. Khanzadeh M, Saeediyan M, Hosseinchari M, Edrissi F. Factor structure and psychometric properties of difficulties in emotional regulation scale.J behav sci. 2012;6(1):87-96.

30. Lovibond PF, Lovibond SH. The structure of negative emotional states: comparison of the Depression Anxiety Stress Scales (DASS) with the Beck Depression and Anxiety Inventories. Behav Res Ther: 1995;33(3):335-43. [PubMed: 7726811]

31. Samani S, Joukar B. A Study On The Reliability And Validity Of The Short Form Of The Depression Anxiety Stress Scale (Dass-21).J Soc Hum Sci Shiraz Univ. 2007;26(3):65-76.

32. Revicki DA, Wood M, Wiklund I, Crawley J. Reliability and validity of the Gastrointestinal Symptom Rating Scale in patients with gastroesophageal reflux disease. Qual Life Res. 1998;7(1):75-83. [PubMed: 9481153]

33. Mazaheri M, Khoshouei MS. Comparison between Psychometric Characteristics of Persian Version of the Gastrointestinal Symptoms Rating Scale in Functional Gastrointestinal Disorders and Normal Groups. Govaresh . 2012;17(1):18-24.

34. Berking M, Orth U, Wupperman P, Meier LL, Caspar F. Prospective effects of emotion-regulation skills on emotional adjustment. J Couns Psychol. 2008;55(4):485-94. doi: 10.1037/a0013589. [PubMed: 22017555]

35. Garnefski N, Kraaij V. Relationships between cognitive emotion regulation strategies and depressive symptoms: A comparative study of five specific samples. Pers Individ Dif. 2006;40(8):165969. doi: 10.1016/j.paid.2005.12.009.

36. Thompson RA, Calkins SD. The double-edged sword: Emotional regulation for children at risk. Dev Psychopathol. 1996;8(01):16382. doi: $10.1017 /$ S0954579400007021.

37. Ekbland AGGA. Effects of mindfulness training on emotion regulation and attention. Durham: Duke University; 2009. 127 p.

38. Bardeen JR, Fergus TA, Orcutt HK. An Examination of the Latent Structure of the Difficulties in Emotion Regulation Scale. J Psychopathol Behav Assess. 2012;34(3):382-92. doi:10.1007/s10862-0129280-y.

39. Niazi AK, Niazi SK. Mindfulness-based stress reduction: a nonpharmacological approach for chronic illnesses. $N$ Am J Med Sci. 2011;3(1):20-3. doi:10.4297/najms.2011.320. [PubMed: 22540058]

40. Baer RA. Mindfulness Training as a Clinical Intervention: A Conceptual and Empirical Review. Clin Psychol: Sci Pr. 2003;10(2):12543. doi:10.1093/clipsy.bpgo15.

41. Grossman P, Niemann L, Schmidt S, Walach H. Mindfulnessbased stress reduction and health benefits. A meta-analysis. J Psychosom Res. 2004;57(1):35-43. doi:10.1016/s0022-3999(03)00573-7. [PubMed: 15256293]

42. Erisman SM, Salters-Pedneault K, Roemer L, editors. Emotion regulation and mindfulness.; Poster presented at the annual convention of the Association for Advancement of Behavior Therapy. Washington, DC (November 17-20, 2005):; 2005; Boston. 


\section{Mazaheri M}

University of Massachusetts;

43. Orgeta V. Emotion dysregulation and anxiety in late adulthood. J Anxiety Disord. 2011;25(8):1019-23. doi: 10.1016/j.janxdis.2011.06.010. [PubMed: 21813262]

44. Coffey KA, Hartman M, Fredrickson BL. Deconstructing Mindfulness and Constructing Mental Health: Understanding Mindfulness and its Mechanisms of Action. Mindfulness. 2010;1(4):235-53. doi:10.1007/s12671-010-0033-2.

45. Lischetzke T, Eid M. Is attention to feelings beneficial or detri- mental to affective well-being? Mood regulation as a moderator variable. Emotion. 2003;3(4):361-77. doi: 10.1037/1528-3542.3.4.361. [PubMed:14674829]

46. Tull MT, Roemer L. Emotion regulation difficulties associated with the experience of uncued panic attacks: evidence of experiential avoidance, emotional nonacceptance, and decreased emotional clarity. Behav Ther. 2007;38(4):378-91. doi: 10.1016/j. beth.2006.10.006. [PubMed:18021952] 